\title{
Adverse events from diagnostic and therapeutic joint injections: a literature review
}

\author{
Peterson, Cynthia ; Hodler, Juerg
}

\begin{abstract}
This review article classifies the various adverse reactions arising from intra-articular injections by severity, diagnostic category, and whether they are due to corticosteroid, local anesthetic or viscosupplementation injections. Life-threatening and serious adverse events from intra-articular injections are rare and range from local complications to systemic afflictions. Measures to reduce the likelihood of an adverse event occurring are outlined and patients with significant features in their clinical histories, predisposing them to adverse events, are highlighted.
\end{abstract}

DOI: https://doi.org/10.1007/s00256-009-0839-y

Posted at the Zurich Open Repository and Archive, University of Zurich

ZORA URL: https://doi.org/10.5167/uzh-125558

Journal Article

Published Version

Originally published at:

Peterson, Cynthia; Hodler, Juerg (2011). Adverse events from diagnostic and therapeutic joint injections: a literature review. Skeletal Radiology, 40(1):5-12.

DOI: https://doi.org/10.1007/s00256-009-0839-y 


\title{
Adverse events from diagnostic and therapeutic joint injections: a literature review
}

\author{
Cynthia Peterson • Juerg Hodler
}

Received: 2 September 2009 /Revised: 2 November 2009/Accepted: 5 November 2009 / Published online: 1 December 2009

(C) ISS 2009

\begin{abstract}
This review article classifies the various adverse reactions arising from intra-articular injections by severity, diagnostic category, and whether they are due to corticosteroid, local anesthetic or viscosupplementation injections. Life-threatening and serious adverse events from intraarticular injections are rare and range from local complications to systemic afflictions. Measures to reduce the likelihood of an adverse event occurring are outlined and patients with significant features in their clinical histories, predisposing them to adverse events, are highlighted.
\end{abstract}

Keywords Therapeutic injections · Joint injections ·

Corticosteroid injections · Viscosupplementation .

Therapeutic joint injections - Adverse events .

Adverse reactions

\section{Introduction}

Injections of local anesthetics into spinal and peripheral joints have been used effectively for many years to help localize the source of a patient's pain. These diagnostic injections, using primarily lidocaine hydrochloride, bupivacaine hydrochloride or ropivacaine hydrochloride, have a substantial body of research to support their value, particularly when done under imaging guidance [1-12]. Therapeutic joint injections, consisting of either a corticosteroid or a hyaluronic acid product (viscosupplementation) along with local anesthetics, have also been used for several

C. Peterson $(\bowtie) \cdot J$. Hodler

Radiology, Orthopaedic University Hospital of Balgrist,

Forchstrasse 340,

8008 Zürich, Switzerland

e-mail: cynthia.peterson@balgrist.ch years $[1-4,6-11,13-18]$, although the level of evidence supporting this therapy is not quite as strong $[2-6,11,13-$ 16]. Arthrography consists of the injection of a contrast agent into a joint and is performed for both diagnostic and therapeutic purposes. It is often used during imagingguided procedures to facilitate accurate needle placement $[1,17]$.

Several papers have reported the various adverse events that may result from diagnostic and therapeutic musculoskeletal injections, including arthrography, and it is generally acknowledged that adverse events are uncommon, being reported in $2.4 \%$ to $12 \%$ of patients. Most of these adverse events are very mild and self-limiting [17-20]. Severe adverse events associated specifically with arthrography have been reported to be exceedingly rare, occurring in approximately $0.03 \%$ of patients as determined in a large, retrospective, questionnaire-based study [20]. Acknowledging that diagnostic and therapeutic joint injections are usually very safe and effective, the purpose of this paper is to briefly outline and categorize the possible adverse events that have been reported and to identify practices that may reduce the likelihood of certain events occurring.

\section{Extra-articular injections}

Although many physicians inject corticosteroids and/or local anesthetics into various joints in their own offices, current guidelines and standards of practice recommend that these injections should be done using imaging guidance, including the use of a contrast agent, to visualize and facilitate correct placement of the needle into the targeted joint [1-13, 17, 21]. The shoulder and knee joints are two areas commonly injected in medical offices without the use of imaging guidance [1, 17, 21-27]. Studies examining the accuracy of 
intended intra-articular injections into these joints, performed either with or without imaging guidance, clearly demonstrate that the accuracy of hitting the intended target is poor if imaging is not used, even when the confidence of the clinician that the correct joint space or bursa has been reached is high [1, 17, 21-27]. Using fluoroscopic imaging to guide needle placement, $93 \%$ of knee injections are intraarticular, compared with only $66 \%$ if a single radiograph is used to evaluate accuracy [23]. The accuracy of entering the knee joint without any imaging guidance has not been ascertained. However, without the use of diagnostic imaging, at best only $69-76 \%$ of subacromial bursal injections hit their intended target [22] with many of these also injecting unintended extra-articular surrounding structures (Fig. 1). Other studies evaluating the accuracy of needle placement for the glenohumeral and subacromial regions of the shoulder report much worse results for hitting the intended target. Only $27-37 \%$ of patients benefitted from injection into the correct anatomical site when imaging guidance was not used $[24,25]$.

The importance of accurately placing the needle into the intended joint space is supported by studies demonstrating that not only are the clinical outcomes for patients much better when the medication is injected into the desired target joint $[25,26]$, but the risk of certain adverse events is reduced [1, 28]. Missing the intended target and injecting into periarticular structures increases the risk of tendon tears, soft tissue atrophy, skin atrophy, depigmentation, and injury to adjacent structures $[1,28]$. Therefore, one way to reduce the likelihood of an adverse event from joint injections is to follow practice guidelines and perform these under appropriate imaging guidance (Fig. 2).

Imaging-guided therapeutic injections are usually performed using fluoroscopy, ultrasound, computed tomography (CT), and most recently, magnetic resonance imaging (MRI) [1-13, 17, 21, 29-32]. Ultrasound shows certain advantages over fluoroscopy, particularly for peripheral joints and related soft tissues [29-31], as it allows avoidance of neurovascular and tendinous structures in the vicinity of the desired target site as well as demonstrating fluid collections. Ultrasound guidance has also been shown to be more accurate than fluoroscopy in allowing placement of the needle into the shoulder joint [30].

\section{Classification of adverse events}

Several reactions have been reported in the literature as adverse events following not only blind injections, but also imaging-guided arthrography or diagnostic and therapeutic joint injections. Most can be categorized as mild, moderate, severe or life threatening, although such a classification system is somewhat subjective with overlap between categories for a few conditions (Tables 1, 2) [33-75]. The life-threatening adverse reactions include air embolism, anaphylactic reactions, hypotension, vasomotor collapse, laryngeal edema, adrenal insufficiency (only linked with corticosteroid injections), and apnea $[17,20,33,53,65-$ 68]. Brain and spinal cord infarctions have been reported when particulate corticosteroids are used during cervical transforaminal injections [12] and for this reason, cervical transforaminal injections have been discontinued at this facility. Life-threatening reactions that can specifically result from local anesthetic injections include central nervous system and cardiac toxicity if the local anesthetic is inadvertently administered into the vascular system or intrathecally [12]. The threshold dose needed to cause this devastating adverse event appears to be much lower if bupivacaine is used rather than lidocaine, as bupivacaine is more cardiotoxic [12]. The life-threatening adverse reactions are so rare, however, that the literature is mostly limited to case reports.
Fig. 1 Imaging-guided injection attempting to target the subacromial bursa. Contrast medium injection demonstrates that the needle is not in the bursa. The needle can thus be repositioned prior to injection of medication

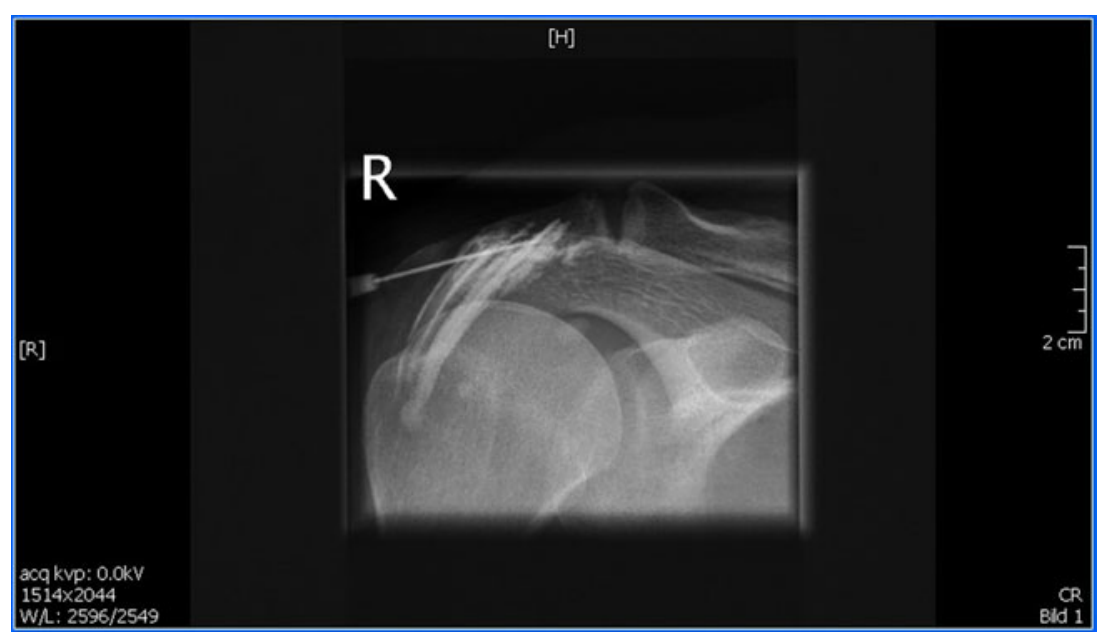




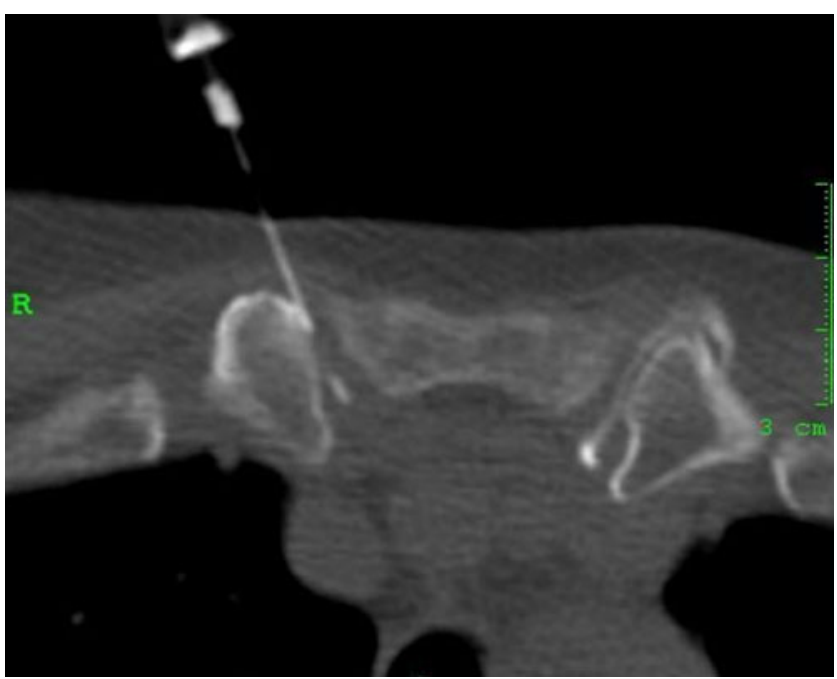

Fig. 2 CT-guided sternoclavicular (SC) joint injections. Contrast medium visualized in the left $\mathrm{SC}$ joint from the first injection confirms correct anatomical placement. The needle is now visualized in the right SC joint. The close proximity of important large vascular structures behind the sternum highlights the necessity of using imaging guidance

Severe reactions are also very uncommon and include those that may result in marked limitation in activity and/or require medical intervention and possible hospitalization. For corticosteroid injections such reactions include septic arthritis, seizures, avascular necrosis, a Charcot-like arthropathy, tendon tears, reactivation of complex regional pain syndrome, and damage to adjacent structures such as nerves, vessels or muscles [34, 55, 56, 68].

Moderate reactions, while also rare, are many and varied, with most requiring limited or no medical intervention and resulting in mild to moderate limitation in activity. For injections containing corticosteroids, moderate reactions may include elevated blood pressure, elevated blood sugar, transient hypophosphatemia, Cushing's syndrome, less severe damage to adjacent structures such as vessels, tendons or nerves, bleeding into the joint, skin necrosis, flare reactions, Tachon syndrome (intense lumbar and/or thoracic pain a few minutes after injection with rapid subsidence of the pain), dysphonia, steroid-induced psychosis (transient), urticaria, insufficiency fractures, and vasovagal reactions [33, 34, 46-50, 54, 59, 62]. Local anesthetics may cause a moderate adverse reaction known as skeletal muscle toxicity. This usually results in complete recovery [12].

Looking specifically at viscosupplementation (hyaluronic acid derivatives), which is used as a treatment for patients with osteoarthritis, particularly of the knee, the severe adverse events reported include septic arthritis, seizures, crystal deposition disease, injury to adjacent structures, and reactivation of complex regional pain

Table 1 Possible adverse reactions from corticosteroid joint injections

\begin{tabular}{|c|c|c|c|}
\hline Mild & Moderate (all are very rare) & Severe (all are very rare) & Life-threatening (all are very rare) \\
\hline $\begin{array}{l}\text { Local pain }{ }^{\mathrm{a}} \\
\text { (most common) }\end{array}$ & Elevated blood pressure & Septic arthritis & Hypotension \\
\hline $\begin{array}{l}\text { Mild local redness } \\
\text { without heat }\end{array}$ & Elevated blood sugar (transient) & $\begin{array}{l}\text { Reactivation of complex } \\
\text { regional pain syndrome }\end{array}$ & Air embolism \\
\hline Local tissue atrophy & Cushing's syndrome & Seizures & Laryngeal edema \\
\hline Cellulitis & Hypophosphatemia (transient) & Avascular necrosis & Apnea \\
\hline Pressure in joint ${ }^{\mathrm{a}}$ & Abnormal uterine bleeding & Charcot-like arthropathy & $\begin{array}{l}\text { Anaphylactic reaction and } \\
\text { vasomotor collapse }\end{array}$ \\
\hline Hypopigmentation & Rupture of local tendons/fascia & Rupture of local tendons/fascia & Adrenal insufficiency \\
\hline Flush reaction & $\begin{array}{l}\text { Damage to local muscles } \\
\text { or other adjacent structures } \\
\text { (nerves, vessels) }\end{array}$ & $\begin{array}{l}\text { Damage to local muscle or } \\
\text { other adjacent structures } \\
\text { (could be moderate or severe) }\end{array}$ & $\begin{array}{l}\text { Spinal cord or brain infarct } \\
\text { from particulate steroids in } \\
\text { cervical epidural block procedure }\end{array}$ \\
\hline \multirow{10}{*}{$\begin{array}{l}\text { Temporary } \\
\text { paresthesia of } \\
\text { the joint (e.g. hip) }\end{array}$} & Hemarthrosis & & \\
\hline & Vasovagal reaction & & \\
\hline & Skin necrosis & & \\
\hline & Tachon syndrome (transient) & & \\
\hline & Dysphonia & & \\
\hline & $\begin{array}{l}\text { Steroid-induced psychosis } \\
\text { (transient) }\end{array}$ & & \\
\hline & Flare reactions & & \\
\hline & Urticaria & & \\
\hline & Herpes zoster & & \\
\hline & Insufficiency fracture & & \\
\hline
\end{tabular}

${ }^{\mathrm{a}}$ Common 
Table 2 Possible adverse reactions from viscosupplementation joint injections

\begin{tabular}{llll}
\hline Mild & Moderate (all are rare) & Severe (all are very rare) & $\begin{array}{c}\text { Life-threatening } \\
\text { (all very rare) }\end{array}$ \\
\hline Local pain $^{\mathrm{a}}$ & $\begin{array}{c}\text { Acute pseudoseptic arthritis } \\
\text { (aka "fflare" reaction or chemical synovitis) } \\
\text { Granulomatous inflammation }\end{array}$ & Septic arthritis & Hypotension \\
Transient inflammatory response & $\begin{array}{c}\text { Reactivation of complex } \\
\text { regional pain syndrome }\end{array}$ & Air embolism \\
Local tissue atrophy & Hemarthrosis & Seizures & Anaphylactic reaction \\
Cramps and restless legs & Vertigo & Crystal deposition arthritis & Laryngeal edema \\
& Adjacent structure injury (nerves, vessels) & Adjacent structure injury & Apnea \\
& Urticaria, puritus & (nerves, vessels) & Vasomotor collapse \\
\hline
\end{tabular}

${ }^{\mathrm{a}}$ Common

syndrome [34, 51-53, 55-57, 67, 72, 73]. Viscosupplementation injections appear to provide a shorter list of moderate adverse events than corticosteroid injections. These include acute pseudoseptic arthritis (described later), granulomatous inflammation, hemarthrosis, vertigo, urticaria, and injury to adjacent structures.

Mild adverse reactions are by far the most common of the post-injection events, require no medical intervention, and are transient. The most frequent mild reaction is local pain. Other minor reactions include pressure in the joint, slight swelling, local tissue atrophy, urticaria, rash, facial or general flushing, hypopigmentation (which usually normalizes over a period of 12 months), reactivation of herpes zoster, flare reactions (explained in a later section), and mild cellulitis $[12,35,36,39,54,60,61,63,64,68,69,74$, 75]. Some of these moderate, severe, and life-threatening reactions deserve more attention and will be briefly discussed in categories.

\section{Injection-induced arthropathies}

In 1985, Newberg et al. [33] reported that the most common adverse reaction following arthrography injections was transient sterile chemical synovitis. It appears from the recent literature that this may now be known as sterile

Table 3 Recommended actions to reduce the risk of adverse events

Recommended action

Use imaging guidance.

Use HA products of lower molecular weight and not from animal sources.

Check for history of CPPD (calcium pyrophosphate crystal deposition) disease.

Don't inject HA product if chondrocalcinosis

visible on routine radiographs.

Apply careful sterile technique and do not inject

if overlying skin infection or psoriasis.

Determine whether or not the patient is immunocompromised.

Check to determine if and when joint replacement surgery is planned. Reconsider use of intra-articular steroids in patients who are likely candidates for joint replacement surgery in the near future. Inform patients of potential risks if injections used.

Determine whether or not the patient has diabetes. Inform diabetic patients that their blood sugar levels will rise significantly shortly after injection and will remain high for a few days.

Determine whether or not this patient is a child with inflammatory arthropathy who needs multiple steroid injections over time.
Adverse event risk effect

Reduced risk of injuring adjacent structures (nerves, vessels, tendons, etc). Reduced risk of granulomatous reaction from HA products. More effective therapeutic action of drug if in the joint.

Decreased risk of 'flare reactions or pseudosepsis.

Viscosupplementation injections may cause an acute flare-up of CPPD (pseudogout) in these patients.

Reduced risk of septic arthritis.

These patients have an increased risk of septic arthritis, herpes zoster.

Preoperative intra-articular steroid injections appear to significantly increase risk of post-operative deep infections.

Hyperglycemia cannot be avoided, but patients must be informed to reduce the anxiety level and to better control their blood sugar during this time.

These patients are at increased risk of Cushing's syndrome. 
synovitis, the "flare reaction" or "pseudosepsis" due to the clinical presentation being similar to true joint sepsis, but supposedly without micro-organisms $[1,37,38]$. However, the descriptions of flare reactions and pseudosepsis in the literature are inconsistent and overlapping. Some authors describe the flare reaction as simply a delayed postinjection transient increase in pain of at least 2 points on a $0-10$ visual analogue scale [39], while others use the terms flare reaction and pseudosepsis interchangeably, describing the symptoms as severe pain, warmth, joint swelling, and effusion [37], symptoms that most definitely mimic true septic arthritis. Flare reactions or pseudosepsis are most appropriately categorized as a moderate adverse event and are self limiting in most cases. They appear to be more common when hyaluronic acid products (viscosupplementation) are injected rather than with corticosteroid injections [37, 38, 40]. It is suggested that hyaluronic acid products of higher molecular weight, such as Hylan GF-20 (Synvisc; Genzyme, Neu-Isenburg, Germany), may be more prone to producing flare reactions and that those that do not contain components from animal sources may be a better alternative [38].

Adding further confusion to the diagnosis of a noninfective adverse event following hyaluronic acid injections is the condition labeled "granulomatous synovitis" [41, 42]. The descriptions of these granulomatous reactions in the literature appear nearly identical to those of flare reactions and pseudosepsis. The patient's symptoms are joint pain, swelling, and warmth developing within $48 \mathrm{~h}$ of injection, gradually resolving without treatment. It is suggested that these granulomatous reactions are due to injection of hyaluronic acid (viscosupplementation) into an adjacent fat pad or subsynovial tissue [37] causing a foreign-body granulomatous inflammation [44]. This adverse event has been reported primarily in the knee as this is the joint where viscosupplementation is most commonly injected [37, 43, 44] in patients suffering from osteoarthritis.

The other non-infective arthritic adverse event that may be induced from hyaluronic acid injections in particular is an acute attack of calcium pyrophosphate dihydrate crystal arthropathy (CPPD or pseudogout) [43, 44]. It is suggested that viscosupplementation injections should not be given to patients with chondrocalcinosis visible on routine radiographs.

The most serious and feared injection-induced arthropathy is septic arthritis with an estimated occurrence rate of 1 in 10,000 to 1 in 50,000 injections $[26,45,70,71]$. The rapid and irreversible joint destruction caused by pyogenic micro-organisms is the reason why this is classified as a serious adverse event. Although any joint injection has an inherent risk of microbial contamination, it is hypothesized that the risk of septic arthritis might be higher in patients receiving corticosteroid injections compared with those receiving viscosupplementation, as corticosteroids are known to have an immunosuppressive effect [71]. Such effects are better known when the steroids are taken orally, however. Obviously, using a sterile technique when performing joint injections is critical and considered standard practice for reducing this risk.

Two retrospective comparative studies found that intraarticular corticosteroid injections into the knees or hips of patients likely to receive joint replacements in the future significantly increased their risk of deep infections of these joints post-operatively compared with patients who did not have these injections [72, 73]. For hip joints the rate of deep post-operative infection was described by the authors as "disturbing," being $10 \%$ of injected patients compared with only $1 \%$ of patients who did not receive intra-articular corticosteroid injections pre-operatively [72]. Knee replacement patients had a $22.2 \%$ chance of wound complications after surgery if they had received intra-articular steroid injections pre-operatively [73]. Neither of these studies described the time period between the patient receiving the steroid injection and the joint replacement surgeries or the number of steroid injections received pre-operatively. Prospective comparative studies on large patient numbers, including the number of injections given and the time frame between the injections and the surgery are indicated to further evaluate these findings. Papavasiliou et al. [73] speculate that the steroid agent might become trapped in the joint and therefore not fully dissolve, thus creating a local reduction in immunity. Although it is very common for osteoarthritis patients to receive intra-articular steroid injections to improve their quality of life and to postpone joint replacement surgeries, clinicians administering intraarticular steroid injections should be aware of this potential risk and perhaps include this information in their informed consent procedures. Others may want to weigh the likelihood of the patient needing a knee or hip joint replacement in the near future before performing these procedures in certain situations $[72,73]$.

\section{Systemic reactions after local intra-articular injection}

The reporting of a variety of systemic reactions after local musculoskeletal injections of corticosteroids demonstrates that these injections have effects beyond the local joint. Intra-articular corticosteroids are rapidly absorbed into the circulation, reaching their maximum blood levels 3-6 h after injection [59]. Patients with controlled type II diabetes who receive an intra-articular steroid injection of methylprednisolone acetate to the knee will have a significant increase in their blood sugar as early as $2-4 \mathrm{~h}$ after injection and lasting as long as 5 days [48]. A rare, transient, but initially frightening systemic complication of intra-articular 
corticosteroid injection is hypophosphatemia [59]. Symptoms include transient paresthesia and weakness of the limbs and dysarthria, coming on hours after the injection [59]. The hypothesized mechanism for this reaction described in the case report was either increased sensitivity to the effects of glucocorticoids or a reduced threshold to the physiological consequences of hypophosphatemia [59].

Secondary Cushing's syndrome, due to intra-articular corticosteroid injections, has also been reported, particularly in pediatric patients with juvenile chronic arthritis who need repeated injections over a prolonged period of time [49-51]. This has also been reported after a single corticosteroid injection in HIV-infected patients who are being treated with the antiretroviral drug ritonavir [52]. A related, but far more serious systemic complication due to intra-articular corticosteroid injections is adrenal insufficiency and failure [51-53]. If unrecognized, this can lead to adrenal crisis, collapse, hypotension, and death [51]. Of the cases reported in the literature, the corticosteroid implicated in each patient was triamcinolone acetonide [51-53].

Intra-articular and epidural corticosteroid injections have also been linked with a flushing reaction of primarily the face and upper trunk with a generalized reaction noted in some patients [74, 75]. This flushing reaction includes redness of the skin and a sensation of warmth, with no other systemic effects, and is reported to be more common in women $[74,75]$. While it has occurred more commonly when triamcinolone is injected, methylprednisolone injections have also produced this effect [74]. The reaction is self-limiting, with the administration of diphenhydramine reducing the duration of this reaction [74].

\section{Prevention of particular adverse events}

Table 3 summarizes the recommendations for reducing the risk of adverse events from intra-articular injections. Using a careful sterile technique when performing joint injections is standard practice and reduces, but does not totally eliminate, the risk of joint infection [1, 17, 76]. Critical components of the sterile technique procedure require that the doctor wear a mask (particularly if he/she has an upper respiratory tract infection), disinfect the hands and wear sterile gloves, disinfect the skin using either an iodinebased solution or alcohol, and drape the area with sterile towels $[1,17,76]$. Avoiding injections when overlying skin infections, wounds or inflammatory diseases such as psoriasis are present is also standard practice to avoid inoculating the joint with micro-organisms. Patients who are likely candidates for joint replacement surgery should be informed of the risks of serious post-operative infections if they receive an intra-articular corticosteroid injection preoperatively. Additionally, clinicians should carefully con- sider whether or not these patients should be treated with intra-articular corticosteroids prior to surgery $[72,73]$.

Flare reactions or pseudosepsis may be decreased by using hyaluronic acid preparations that are of lower molecular weight and are not derived from animal products [38]. As several cases of hyaluronic acid-induced acute CPPD (pseudogout) have been reported [43, 44], it is suggested that this treatment be avoided if chondrocalcinosis is already visualized on routine radiographs of the involved joint to prevent acute exacerbation of the symptoms.

Systemic reactions other than hyperglycemia in diabetics are extremely rare and precautions cannot be taken at this point in time to reduce their likelihood. However, the signs and symptoms of adrenal insufficiency and hypophosphatemia must be readily recognized so that appropriate confirming diagnostic tests and treatment or reassurance can be provided to the patient $[51-53,59]$. Diabetic patients must be informed about the likely changes in their blood sugar levels and that these may last for a few days after injection.

Finally, using imaging guidance for diagnostic and therapeutic joint injections is imperative to reduce the risk of damaging adjacent structures as well as achieving the best clinical effect from the medication reaching the intended target. Additionally, the risk of granulomatous synovitis secondary to extra-articular injection of hyaluronic acid will be reduced if imaging guidance is applied. Because triamcinolone hexacetonide is more likely to cause local tissue necrosis, tendon rupture, and calcification if injected in an extra-articular location, it is imperative that imaging guidance be used when this corticosteroid is injected [12]. It is also suggested that triamcinolone hexacetonide, a very effective steroid with a relatively long clinical benefit, be administered by a more experienced radiologist [12].

\section{References}

1. Malfair D. Therapeutic and diagnostic joint injections. Radiol Clin N Am. 2008;46:439-453.

2. Rupert MP, Lee M, Manchikanti L, Datta S, Cohen SP. Evaluation of sacroiliac joint interventions: a systematic appraisal of the literature. Pain Physician. 2009;12:399-418.

3. Falco FJE, Erhart S, Wargo BW, Bryce DA, Atluri S, Datta S, et al. Systematic review of diagnostic utility and therapeutic effectiveness of cervical facet joint interventions. Pain Physician. 2009; 12:323-344.

4. Boswell MV, Colson JD, Sehgal N, Dunbar EE, Epter R. A systematic review of therapeutic facet joint interventions in chronic spinal pain. Pain Physician. 2007;10:229-253.

5. Sehgal N, Dunbar EE, Shah RV, Colson J. Systematic review of diagnostic utility of facet (zygapophysial) joint injections in chronic spinal pain: an update. Pain Physician. 2007;10:213-228.

6. Atluri S, Datta S, Falco FJE, Lee M. Systematic review of diagnostic utility and therapeutic effectiveness of thoracic facet joint interventions. Pain Physician. 2008;11:611-629. 
7. Karnezis IA. Minimally invasive therapeutic interventional procedures in the spine: an evidence-based review. Surg Technol Int. 2008;17:259-268.

8. Boswell MV, Trescot AM, Datta S, Schultz DM, Hansen HC, Abdi S, et al. Interventional techniques: evidence-based practice guidelines in the management of chronic spinal pain. Pain Physician. 2007;10:7-111.

9. Chou R, Atlas SJ, Stanos SP, Rosenquist RW. Nonsurgical interventional therapies for low back pain. A review of the evidence for an American Pain Society clinical practice guideline. Spine. 2009;34:1078-1093.

10. Manchikanti L, Singh V, Falco FJE, Cash KA, Pampati V. Lumbar facet joint nerve blocks in managing chronic facet joint pain: oneyear follow-up of a randomized, double-blind controlled trial: clinical trial NCT00355914. Pain Physician. 2008;11:121-132.

11. Hansen HC, McKenzie-Brown AM, Cohen SP, Swicegood JR, Colson JD, Manchikanti L. Sacroiliac joint interventions: a systematic review. Pain Physician. 2007;10:165-184.

12. MacMahon PJ, Eustace SJ, Kavanagh EC. Injectable corticosteroid and local anesthetic preparations: a review for radiologists. Radiology. 2009;252:647-661.

13. Buchbinder R, Green S, Youd JM. Corticosteroid injections for shoulder pain. Cochrane Database of Systematic Reviews 2003, Issue 1. Art. No.: CD004016. doi:10.1002/14651858.CD004016.

14. Gaujoux-Viala C, Dougados M, Gossec L. Efficacy and safety of steroid injections for shoulder and elbow tendonitis: a metaanalysis of randomized controlled trials. Ann Rheum Dis. 2008; doi:10.1136/ard.2008.099572. published online 3 Dec 2008.

15. Koester MC, Dunn WR, Kuhn JE, Spindler KP. The efficacy of subacromial corticosteroid injection in the treatment of rotator cuff disease: a systematic review. J Am Acad Orthop Surg. 2007;15:3-11.

16. Arroll B, Goodyear-Smith F. Corticosteroid injections for painful shoulder: a meta-analysis. Br J Gen Pract. 2005;55:224-228.

17. Tehranzadeh J, Mossop EP, Golshan-Momeni M. Therapeutic arthrography and bursography. Orthop Clin N Am. 2006;37:393-408.

18. Creamer P. Intra-articular corticosteroid treatment in osteoarthritis. Opin Rheumatol. 1999;11:417-421.

19. Saupe N, Zanetti M, Pfirmann CWA, Weis T, Schwenke C, Hodler J. Pain and other side effects after MR arthrography: prospective evaluation in 1085 patients. Radiology. 2009;250:830-838.

20. Hugo PC III, Newberg AH, Newman JS, Wetzner SM. Complications of arthrography. Semin Musculoskelet Radiol. 1998;2:345-348.

21. Partington PF, Broome GH. Diagnostic injection around the shoulder: hit and miss? A cadaveric study of injection accuracy. J Shoulder Elbow Surg. 1998;7:147-150.

22. Henkus HE, Lodewijck PJ, Cobben MD, Coerkamp EG, Nelissen RGHH, van Arkel ERA. The accuracy of subacromial injections: a prospective randomized magnetic resonance imaging study. Arthroscopy. 2006;22:277-282.

23. Jackson DW, Evans NA, Thomas BM. Accuracy of needle placement into the intra-articular space of the knee. J Bone Jt Surg Am. 2002;84:1522-1527.

24. Sethi PM, Kingston S, Elattrache N. Accuracy of anterior intraarticular injection of the glenohumeral joint. Arthroscopy. 2005;21:77-80.

25. Eustace JA, Brophy DP, Gibney RP, Bresnihan B, FitzGerald O. Comparison of the accuracy of steroid placement with clinical outcome in patients with shoulder symptoms. Ann Rheum Dis. 1997;56:59-63.

26. Jones A, Regan M, Ledingham J, Pattrick M, Manhire A, Doherty M. Importance of placement of intra-articular steroid injections. BMJ. 1993;307:1329-1330.

27. Yamakado K. The targeting accuracy of subacromial injection to the shoulder: an arthrographic evaluation. Arthroscopy. 2002;18:887-891.
28. Dussault RG, Kaplan PA, Anderson MW. Fluoroscopy-guided sacroiliac joint injections. Radiology. 2000;214:273-277.

29. Reach JS, Easley ME, Chuckpaiwong B, Nunley JA II. Accuracy of ultrasound guided injections in the foot and ankle. Foot Ankle Int. 2009;30:239-242.

30. Rutten MJ, Collins JM, Maresch BJ, Smeets JH, Janssen CM, Kiemeney LA, et al. Glenohumeral joint injection: a comparative study of ultrasound and fluoroscopically guided techniques before MR arthrography. Eur Radiol. 2009;19:722-730.

31. Lohman M, Vasenius J, Niemen O. Ultrasound guidance for puncture and injection in the radiocarpal joint. Acta Radiol. 2007;48:744-747.

32. Cimmino MA, Grassi W, Cutolo M. Modern imaging techniques: a revolution for rheumatology practice. Best Pract Res Clin Rheumatol. 2008;22:951-959.

33. Newberg AH, Munn CS, Robbins AH. Complications of arthrography. Radiology. 1985;155:605-606.

34. Nichols AW. Complications associated with the use of corticosteroids in the treatment of athletic injuries. Clin J Sport Med. 2005; 15:370-375.

35. Marti P, Molinari L, Bolt IB, Seger R, Saurenmann RK. Factors influencing the efficacy of intra-articular steroid injections in patients with juvenile idiopathic arthritis. Eur J Pediatr. 2008;167:425-430.

36. Cardone DA, Tallia AF. Joint and soft tissue injection. Am Fam Phys. 2002;66:283-288.

37. Marino AA, Waddell DD, Kolomytkin OV, Pruett S, Sadasivan KK, Albright JA. Assessment of immunologic mechanisms for flare reactions to Synvisc. Clin Orthop Relat Res. 2006;442:187-194.

38. Roos J, Epaulard O, Juvin R, Chen C, Pavese P, Brion JP. Acute pseudoseptic arthritis after intraarticular sodium hyaluronan. Jt Bone Spine. 2004;71:352-354.

39. Goldfarb CA, Gelberman RH, McKeon K, Chia B, Boyer MI. Extra-articular steroid injection: early patient response and the incidence of flare reaction. J Hand Surg. 2007;32A:1513-1520.

40. Goldberg VM, Coutts RD. Pseudoseptic reactions to hylan viscosupplementation: diagnosis and treatment. Clin Orthop Relat Res. 2004;419:130-137.

41. Michou L, Job-Deslandre C, de Pinieux G, Kahan A. Granulomatous synovitis after intraarticular Hylan GF-20. A report of two cases. Joint Bone Spine. 2004;71:438-440.

42. Chen AL, Desai P, Adler EM, Cesare PE DI. Granulomatous inflammation after Hylan G-F 20 viscosupplementation of the knee: a report of six cases. J Bone Jt Surg Am. 2002;84:1142-1147.

43. Kroesen S, Schmid W, Theiler R. Induction of an acute attack of calcium pyrophosphate dihydrate arthritis by intra-articular injection of Hyaln G-F 20 (Synvisc). Clin Rheumatol. 2000;19:147-149.

44. Hammesfahr JF, Knopf AB, Stitik T. Safety of intra-articular hyaluronates for pain associated with osteoarthritis of the knee. Am J Orthop. 2003;32:277-283.

45. Hunter JA, Blyth TH. A risk-benefit assessment of intra-articular corticosteroids in rheumatic disorders. Drug Saf. 1999;21:353-365.

46. Hajjioui A, Nys A, Poiraudeau S, Revel M. An unusual complication of intra-articular injection of corticosteroids: Tachon syndromes. Two case reports. Ann Readapt Med Phys. 2007;50:721-723.

47. Berthelot JM, Tortellier L, Guillot P, Prost A, Caumon JP, Glemarac J, et al. (Société de Rhumatologie de l'Ouest). Tachon syndrome (suracute back and/or thoracic pain following local injections of corticosteroids). A report of 318 French cases. Joint Bone Spine. 2004;72:66-68.

48. Habib GS, Bashir M, Jabbour A. Increased blood glucose levels following intra-articular injection of methylprednisolone acetate in patients with controlled diabetes and symptomatic osteoarthritis of the knee. Ann Rheum Dis. 2008;67:1790-1791.

49. Gondwe JS, Davidson JE, Deeley S, Sills J, Cleary AG. Secondary Cushing's syndrome in children with juvenile idio- 
pathic arthritis following intra-articular triamcinolone acetonide administration. Rheumatology. 2005;44:1457-1458.

50. Kumar S, Singh RJ, Reed AM, Lteif AN. Cushing's syndrome after intra-articular and intradermal administration of triamcinolone acetonide in three pediatric patients. Pediatrics. 2004;113:1820-1824.

51. Hameed R, Zacharin MR. Cushing syndrome, adrenal suppression and local corticosteroid use. J Paediatr Child Health. 2006;42:392-394.

52. Yombi JC, Maiter D, Belkhir L, Nzeusseu A, Vandercam B. Iatrogenic Cushing's syndrome and secondary adrenal insufficiency after a single intra-articular administration of triamcinolone acetonide in HIV-infected patients treated with ritonavir. Clin Rheumatol. 2008;27:S79-82.

53. Schott S, Schnauder G, Müssig K. Secondary adrenal insufficiency after local injections of triamcinolone acetonide. Dtsch Med Wochenschr. 2009;134:298-301.

54. Fernandes R, Malliah R, Stitik TP, Rozdeba P, Lambert WC, Schwartz RA. Herpes zoster following intra-articular corticosteroid injection. Acta Dermatoven APA. 2009;18:28-30.

55. Schindler C, Paessler L, Eckelt U, Kirch W. Severe temporomandibular dysfunction and joint destruction after intra-articular injection of triamcinolone. J Oral Pathol Med. 2005;34:184-186.

56. Kontovazenitis PI, Starantzis KA, Soucacos PN. Major complication following minor outpatient procedure: osteonecrosis of the knee after intraarticular injection of cortisone for treatment of knee arthritis. J Surg Orthop Adv. 2009;18:42-44.

57. Breit W, Frosch M, Meyer U, Heinecke A, Ganser G. A subgroupspecific evaluation of the efficacy of intraarticular triamcinolone hexacetonide in juvenile chronic arthritis. J Rheumatol. 2000;27:2696-2702.

58. Neidel J, Boehnke M, Küster RM. The efficacy and safety of intraarticular corticosteroid therapy for coxitis in juvenile rheumatoid arthritis. Arthritis Rheum. 2002;46:1620-1628.

59. Roberts-Thomson KC, Iyngkaran G, Fraser RJ. Intra-articular glucocorticoid injections: an unusual cause of transient hypophosphataemia. Rheumatol Int. 2006;27:95-96.

60. Rogojan C, Hetland ML. Depigmentation - a rare side effect to intraarticular glucocorticoid treatment. Clin Rheumatol. 2004;23:373-375.

61. Buekelman T, Arabshahi B, Cahill AM, Daye RD, Cron RQ. Benefit of intraarticular corticosteroid injection under fluoroscopic guidance for subtalar arthritis in juvenile idiopathic arthritis. J Rheumatol. 2006;33:2330-2336.
62. Robinson DE, Harrison-Hansley E, Spencer RF. Steroid psychosis after an intra-articular injection. Ann Rheum Dis. 2000;59:927.

63. Pollock B, Wilkinson SM, MacDonald Hill SP. Chronic urticaria associated with intra-articular methylprednisolone. Br J Dermatol. 2001;144:1228-1230.

64. Zaman FM, Wong M, Slipman CW, Ellen MI. Dysphonia associated with shoulder steroid injection. Am J Phys Med Rehabil. 2005;84:307-309.

65. Mace S, Vadas P, Pruzanski W. Anaphylactic shock induced by intraarticular injection of methylprednisolone acetate. J Rheumatol. 1997;24:1191-1194.

66. Karsh J, Yang WH. An anaphylactic reaction to intra-articular triamcinolone: a case report and review of the literature. Ann Allergy Asthma Immunol. 2003;90:254-258.

67. Costello RF, Beall DP, Van Zaadt BL, Stapp AM, Martin HD, Steury SW. Contrast reaction from hip arthrogram. Emerg Radiol. 2007;14:59-61.

68. Kumar N, Newman RJ. Complications of intra- and peri-articular steroid injections. Br J Gen Pract. 1999;49:465-466.

69. Waddell DD. The tolerability of viscosupplementation: low incidence and clinical management of local adverse events. Curr Med Res Opin. 2003;19:575-589.

70. Lequerré T, Nouvellon M, Kraznowska K, Bruno MC, Vittecoq O, Mejjad O, et al. Septic arthritis due to Actinomyces naeslundii: report of a case. Joint Bone Spine. 2002;69:499-501.

71. Albert C, Brocq O, Gerard D, Roux C, Euller-Ziegler L. Septic knee arthritis after intra-articular hyaluronate injection. Two case reports. Joint Bone Spine. 2006;73:205-207.

72. Kaspar $\mathrm{S}$, de $\mathrm{V}$ de Beer $\mathrm{K}$. Infection in hip arthroplasty after previous injection of steroid. J Bone Jt Surg (Br). 2005;87-B:454- 457.

73. Papavasilious AV, Isaac DL, Marimuthu R, Skyrme A, Armitage A. Infection in knee replacements after previous injection of intraarticular steroid. J Bone Jt Surg (Br). 2006;88-B:321-323.

74. DeSio JM, Kahn CH, Warfield CA. Facial flushing and/or generalized erythema after epidural steroid injection. Anesth Analg. 1995;80:617-619.

75. Pattrick M, Doherty M. Facial flushing after intra-articular injection of steroid. Br Med J (Clin Res Ed). 1987;295:1380.

76. Kappstein I. Nosokomiale Infektionen: Prävention, LaborDiagnostik, Antimikrobielle Therapie. 3rd edn. Germering/ Munich, Germany: Zuckschwerdt; 2004. p. 65-69. 